\title{
INOVAÇÕES PATENTEADAS NO ÂMBITO DAS TECNOLOGIAS LIMPAS: ESTUDO DE CASOS DEPOSITADOS NO PROGRAMA DE PILOTO DE PATENTES VERDES DO INPI
}

\author{
D. A. SANTOS $^{1}$, M. E. M. MARTINEZ ${ }^{1}$, P. C. REIS ${ }^{1}$ e C. C. OSAWA ${ }^{1}$ \\ ${ }^{1}$ Instituto Nacional de Propriedade Industrial (INPI), Diretoria de Patentes \\ E-mail para contato: dsaints@inpi.gov.br
}

\begin{abstract}
RESUMO - A busca por rotas inventivas para a produção de biocombustíveis, a produção de hexanoato de etila a partir de resíduos industriais, aproveitamento de madeira de demolição, Processo de esterificação direta de ácidos graxos livres via ácido sulfúrico e desidratantes sulfato de sódio ou sulfato de potássio para a produção de biodiesel de elevada pureza são exemplos ímpares das inovações patenteadas no Brasil por meio do Programa Piloto de Patentes Verdes (PV). O PV foi criado no Brasil pelo INPI em 2012, tendo como objetivo reduzir o tempo de espera do registro de patentes que apresentem tecnologias que diminuam os efeitos das mudanças climáticas globais, além de identificar as tecnologias verdes e estimular o seu licenciamento, de maneira a levar a inovação para quem precisa dessa ferramenta. No presente trabalho foi conduzido um estudo de três casos: o que teve sua patente concedida em menor tempo, maior tempo e tempo intermediário das patentes concedidas até 30/04/2014. Destas, todas obtiveram a cartapatente em menos de 02 anos do Programa. O objetivo é tratar do PV para o âmbito acadêmico e demonstrar as condições, de se obter um patenteamento em um prazo menor do que a publicação em um periódico nível A1 garantindo além da publicidade a proteção patentária.
\end{abstract}

\section{INTRODUÇÃO}

A preocupação com o crescimento populacional, o combate à pobreza absoluta, os novos desafios da economia e o impacto das atividades humanas sobre o meio ambiente, destacaram-se de forma progressiva. No ano de 1994, vários países se uniram em um tratado internacional denominado Quadro das Nações Unidas sobre Mudanças Climáticas (UNFCCC, da sigla em inglês). Nesse tratado, foram iniciadas discussões sobre o que poderia ser feito para reduzir o aquecimento global.

Vários países, inclusive o Brasil, aprovaram, durante a ECO-92, uma adição ao referido Quadro das Nações Unidas: o Protocolo de Quioto. Constitui-se como um tratado internacional com compromissos rígidos para a redução da emissão dos gases que agravam o efeito estufa. Tais gases são considerados como as causas antropogênicas do aquecimento global, de acordo com a maioria das investigações científicas. (UNFCCC, 2014). O Protocolo de Quioto entrou em vigor em 2005, estabelecendo uma série de compromissos juridicamente vinculativos, incluindo a redução das emissões dos gases do efeito de estufa no período de 2008 a 2012, a fim de atingir uma taxa de emissão cerca de 5\% menor do que em 1990 (CERVINO; SÁNCHEZ, 2010). 


\section{9 a 22 de outubro de 2014 \\ Florianópolis/SC}

As mudanças climáticas se constituem em um gravíssimo problema mundial e seu lastro incidirá no futuro do planeta de forma muito séria, incidentemente nos recursos básicos para a vida nos ecossistemas e, obviamente, em todas as sociedades humanas (DURÁN, 2010). Trata-se, portanto, do maior desafio ambiental e de desenvolvimento do século XXI.

É de consenso de várias autoridades governamentais e não-governamentais, tanto de países desenvolvidos como de países em desenvolvimento (IDSO \& SINGER, 2009), que as fontes não renováveis, tais como o carvão e outros combustíveis fósseis, ainda continuarão tendo papel relevante na matriz energética global. Sendo assim, faz-se necessário buscar o equilíbrio entre segurança energética e segurança climática. Entretanto, essas mesmas autoridades são categóricas ao afirmar a necessidade premente de buscar tecnologias mais limpas, ditas "ambientalmente amigáveis" (EST), que possibilitem a comunhão entre abastecimento energético e proteção ambiental, e, por conseguinte, a redução de emissões de gases do efeito estufa e a minimização dos efeitos das mudanças climáticas.

Observando-se este cenário, compreende-se que, mais do que existir, tais tecnologias "ambientalmente amigáveis" precisam ser identificadas e difundidas. Para isso, ressalta-se a partir de agora a importância e a relevância da pesquisa, do desenvolvimento e da disseminação das informações tecnológicas envolvidas com as tecnologias que apresentam aspectos significativos para o enfrentamento das mudanças climáticas, quer sejam tecnologias envolvidas com questões de adaptação, que sejam questões relacionadas com a mitigação e redução dos efeitos das mudanças climáticas.

Sendo assim, nota-se que o Sistema de Propriedade Industrial, tal como se apresenta nos dias atuais, em uma modalidade específica, conhecida como "Sistema Patentário", revela-se como um forte aliado à difusão e à transferência de tecnologias, cujo foco é a mitigação e/ou a adaptação às mudanças climáticas.

As Patentes Verdes conceitualmente são patentes que contemplam e incorporam conceitos das tecnologias "verdes" e tecnologias "limpas", que tem o potencial de ser trazer benefícios ao meio ambiente ao tratar, mitigar, reduzir, ou impedir a deterioração ambiental.

As patentes verdes aparecem como uma parte de medidas para combater a mudança climática, pois maximiza o apoio a invenções que poderiam ter um impacto significativo no combate às alterações climáticas. O princípio que rege o objetivo das patentes "verdes" é o de oferecer às empresas inovadoras em tecnologias "verdes" a chance de obter direitos de patente de alta qualidade em menos tempo.

Com o objetivo de contribuir para o combate às mudanças climáticas globais, o INPI incluiu no seu portfólio de projetos prioritário do INPI para redução do "Backlog", o projeto específico designado "Implementação do Programa de Exames de Patentes Verdes". Neste projeto foi adotado como definição de tecnologias verdes uma lista de tecnologias baseada na definição da OMPI (green inventory) adaptada a LPI: (i) produção de energia alternativa; (ii) transporte; (iii) conservação de energia; (iv) gestão de resíduos; (v) agricultura. 


\section{Programa Piloto de Patentes Verdes no Brasil - $1^{\text {a }}$ Fase}

O INPI deu início em 17 de abril de 2012, ao Programa Piloto de Patentes Verde, com a resolução n²83/2012. O programa tanto visou acelerar o exame dos pedidos de patentes verdes, bem como permitir a identificação das tecnologias verdes requisitadas, buscando assim não apenas acelerar decisões em matéria de pedidos de patentes de invenção, como também possibilitar a identificação de novas tecnologias que possam ser rapidamente usadas pela sociedade, buscando estimular o seu licenciamento e incentivar a inovação no país. Foram 90 pedidos com solicitações protocoladas.

Os critérios para ingresso no programa foram:

- Pedidos depositados a partir de Janeiro de 2011;

- Apresentar Petição específica para Solicitação para ingresso no Programa Piloto de Patentes Verdes;

- Ter feito Pedido de Publicação antecipada e Pedido de Exame;

- Somente Pedidos de Patente de Invenção (PI);

- Somente Pedidos Nacionais e CUP ${ }^{1}$;

- Estar relacionado a Tecnologias Verdes conforme Definição do INPI. A listagem destas tecnologias é apresentada na resolução;

- Possuir no máximo 3 Reivindicações Independentes e 15 Reivindicações Totais;

\section{Programa Piloto de Patentes Verdes no Brasil - $2^{\mathrm{a}}$ Fase}

Como Resolução n²83/2012 possuía uma validade da um ano, em abril de 2013 foi realizada uma nova avaliação nos critérios. Como não as vagas não foram preenchidas, ocorreu um aumento do universo antes delimitado para o Programa Piloto de Patentes Verdes. A nova resolução publicada, n ${ }^{\circ} 3 / 2013$, não apresentou limite para a data de depósito. Ao longo da $2^{\mathrm{a}}$ fase do Programa Piloto de Patentes Verdes, se fez uma nova ampliação de critérios, permitindo agora a participação de pedidos de patente de modelo de utilidade, resolução n¹22/2013. Foram 137 pedidos com solicitações protocoladas.

\section{Programa Piloto de Patentes Verdes no Brasil - $3^{\text {a }}$ Fase}

\footnotetext{
${ }^{1}$ A Convenção de Paris (CUP), que em 2005 que contava com 169 países membros, garante o direito de prioridade para os depositantes de pedidos de patente em um dos países signatários desde que sejam depositados no exterior em até 12 meses.
} 
A resolução ${ }^{\circ} 131 / 2014$ estendeu o Programa Piloto de patentes Verdes por mais um ano e possibilitou o ingresso de pedidos $\mathrm{PCT}^{2}$, estando valendo os seguintes critérios:

- Apresentar Petição específica para Solicitação para ingresso no Programa Piloto de Patentes Verdes;

- Ter feito Pedido de Publicação antecipada e Pedido de Exame;

- Pedidos de Patente de Invenção (PI) e Modelo de Utilidade (MU);

- Pedidos Nacionais (BR, CUP e PCT);

- Estar relacionado a Tecnologias Verdes conforme Definição do INPI. A listagem destas tecnologias é apresentada na resolução;

- Possuir no máximo 3 Reivindicações Independentes e 15 Reivindicações Totais.

\section{METODOLOGIA}

Para o estudo de casos foram coletadas informações da RPI (Revista de Propriedade Industrial) disponibilizadas no site do INPI (http://revistas.inpi.gov.br/rpi/) a partir do número do pedido e conforme os despachos publicados. A Tabela 1 apresenta a lista de despachos para acompanhamento dos pedidos nas publicações considerados neste estudo.

Tabela 1 - Lista de despachos buscados na RPI para efeito deste estudo

\begin{tabular}{|c|c|}
\hline Código & Despacho \\
\hline 2.1 & Pedido de Patente ou Certificado de Adição de Invenção depositado \\
\hline 3.1 & Publicação do Pedido de Patente ou de Certificado de Adição de Invenção \\
\hline 3.2 & Publicação Antecipada do Pedido \\
\hline 27.1 & Notificação de Solicitação para Participação no Programa de Patentes Verdes \\
\hline 27.2 & Solicitação para Participação no Programa de Patentes Verdes Concedida \\
\hline 27.3 & Solicitação para Participação no Programa de Patentes Verdes Negada \\
\hline 6.1 & Parecer Técnico de Exigência \\
\hline 7.1 & Conhecimento de Parecer Técnico de Ciência \\
\hline 9.1 & Parecer Técnico de Deferimento \\
\hline 9.2 & Parecer Técnico de Indeferimento \\
\hline 12.6 & Notificação de entrada Recurso \\
\hline
\end{tabular}

2 O Tratado de Cooperação de Patentes (PCT, 2014), foi firmado em 19 de junho de 1970, em Washington, auxilia os candidatos na busca de potencial proteção internacional de patentes para seus inventos, ajuda os escritórios de patentes com decisões à concessão de patentes, e facilita o acesso do público a uma grande quantidade de informações técnicas relativas a essas invenções. Mediante a apresentação de um pedido de patente internacional sob o PCT, os candidatos (convenção de Paris) e PCT; e, as principais tecnologias com base na classificação internacional de patente. Para as quatro principais categorias foi realizada uma análise mais aprofundada das tecnologias relevantes do setor de perfuração de solo ou rocha para obtenção de óleo. 


\section{9 a 22 de outubro de 2014 \\ Florianópolis/SC}

Foram escolhidos 3 pedidos de patente participantes do Programa Piloto de Patentes Verdes (PV) já deferidos, apresentados na Tabela 2. Das Patentes Verdes concedidas até 30 de abril de 2014 foi escolhido o concedido em menor tempo, em maior tempo e o outro em tempo intermediário.

Tabela 2 - Pedidos de Patente Analisados neste estudo

\begin{tabular}{|c|c|}
\hline Número do pedido & Título do Pedido \\
\hline PI1104733-0 & $\begin{array}{c}\text { Processo de esterificação direta de ácidos graxos livres via ácido sulfúrico e } \\
\text { desidratantes sulfato de sódio ou sulfato de potássio para a produção de } \\
\text { biodiesel de elevada pureza }\end{array}$ \\
\hline BR102012022280-9 & $\begin{array}{c}\text { Processo para reaproveitamento e impermeabilização de madeira de } \\
\text { demolição }\end{array}$ \\
\hline PI1101711-2 & $\begin{array}{c}\text { Processo de produção de hexanoato de etila por via biológica } \\
\text { utilizando meio sintético e resíduos agroindustriais e seu uso }\end{array}$ \\
\hline
\end{tabular}

\section{RESULTADOS E DISCUSSÕES}

O primeiro caso se refere ao pedido PI1104733-0 depositado em 19/08/2011 que trata de um processo de produção de biodiesel, a partir de ácidos graxos livres, em operação contínua ou descontínua em reator aberto ou fechado; recorrendo, para tal fim, à aplicação do ácido sulfúrico $\left(\mathrm{H}_{2} \mathrm{SO}_{4}\right)$ mais sulfato de sódio $\left(\mathrm{Na}_{2} \mathrm{SO}_{4}\right)$ ou bisulfato de sódio $\left(\mathrm{HNaSO}_{4}\right)$ mais sulfato de sódio ou ácido sulfúrico mais sulfato de potássio $\left(\mathrm{K}_{2} \mathrm{SO}_{4}\right)$ ou bisulfato de potássio $\left(\mathrm{HKSO}_{4}\right)$ mais sulfato de potássio em meio alcoólico esterificante. Este pedido foi aceito no PV por se tratar de uma tecnologia verde identificado como "Energia Alternativa" incluída no item (i) do "green inventory" da OMPI; e levou 131 dias para ser concedido.

O segundo caso se refere ao pedido BR102012022280-9 depositado em 04/09/2012 que trata de um processo que visa viabilizar o reaproveitamento de madeiras que foram empregadas durante a execução de obras de construção civil, onde estas madeiras são utilizadas na construção de formas para concretagem, andaimes, tapumes entre outros. Dito que, o referido processo compreende o corte estratégico dos restos de madeira recolhidos na obra na forma de sarrafos, os quais são inter-colados lado a lado com resina epóxi, e em seguida recebem a aplicação de mais uma camada de resina epóxi; uma manta de fibra de vidro, e por fim, mais uma camada de resina epóxi. Este pedido foi aceito no PV por se tratar de uma tecnologia verde identificado como "Gerenciamento de Resíduos" incluída no item (iv) (gestão de resíduos) do "green inventory" da OMPI; e levou 489 dias para ser concedido.

O terceiro caso se refere ao pedido PI1101711-2 depositado em 25/04/2011 que trata da utilização de dois importantes resíduos agroindustriais (manipueira e bagaço de malte) para a produção de hexanoato de etila pela linhagem Neurospora sitophila FGSC 1135. A presente invenção ainda revela que o processo de produção de hexanoato de etila por via biotecnológica utilizando meios sintético e resíduos agroindustriais tem como uma das principais aplicações a produção de aroma natural visando aplicação direta em produtos como, por exemplo, cosméticos e produtos 
alimentícios. Este pedido foi aceito no PV por se tratar de uma tecnologia verde identificado como "Reaproveitamento de Resíduos" incluída no item (iv) (gestão de resíduos) do "green inventory" da OMPI; e levou 627 dias para ser concedido.

Tabela 3 - Demais Dados dos Pedidos de Patente Analisados neste estudo

\begin{tabular}{|c|c|c|c|c|c|c|c|c|}
\hline $\mathbf{N}^{\circ}$ do pedido & $\begin{array}{l}\text { data de } \\
\text { depósito }\end{array}$ & $\begin{array}{c}\text { Data da } \\
\text { solicitação } \\
\text { de ingresso } \\
\text { no PV }\end{array}$ & 27.1 & 27.2 & $\begin{array}{c}1^{\circ} \text { exame } \\
(6.1 \text { ou } 7.1)\end{array}$ & $\begin{array}{c}2^{\circ} \text { exame } \\
(6.1 \text { ou } 7.1)\end{array}$ & 9.1 & IPC \\
\hline PI1104733-0 & $19 / 08 / 11$ & $25 / 04 / 13$ & $07 / 05 / 13$ & $23 / 07 / 13$ & ----------- & |------------ & $03 / 09 / 13$ & C11C3/00 \\
\hline BR102012022280-9 & $04 / 09 / 12$ & $19 / 09 / 12$ & $19 / 03 / 13$ & $24 / 04 / 13$ & $16 / 07 / 13$ & $12 / 11 / 13$ & $21 / 01 / 14$ & B32B21/00 \\
\hline PI1101711-2 & $25 / 04 / 11$ & $11 / 05 / 12$ & $31 / 07 / 12$ & $04 / 09 / 12$ & $05 / 03 / 13$ & $20 / 08 / 13$ & $28 / 01 / 14$ & C12P7/62 \\
\hline
\end{tabular}

A Figura 1 ilustra a distribuição dos pedidos de patentes do PV nas áreas tecnológicas: gerenciamento de resíduos (52\%), agricultura (22\%); energia alternativa (21\%); e, conservação de energia e transporte que juntas representam menos de 5\%, considerando os dados levantados até dia 30 de abril de 2014.

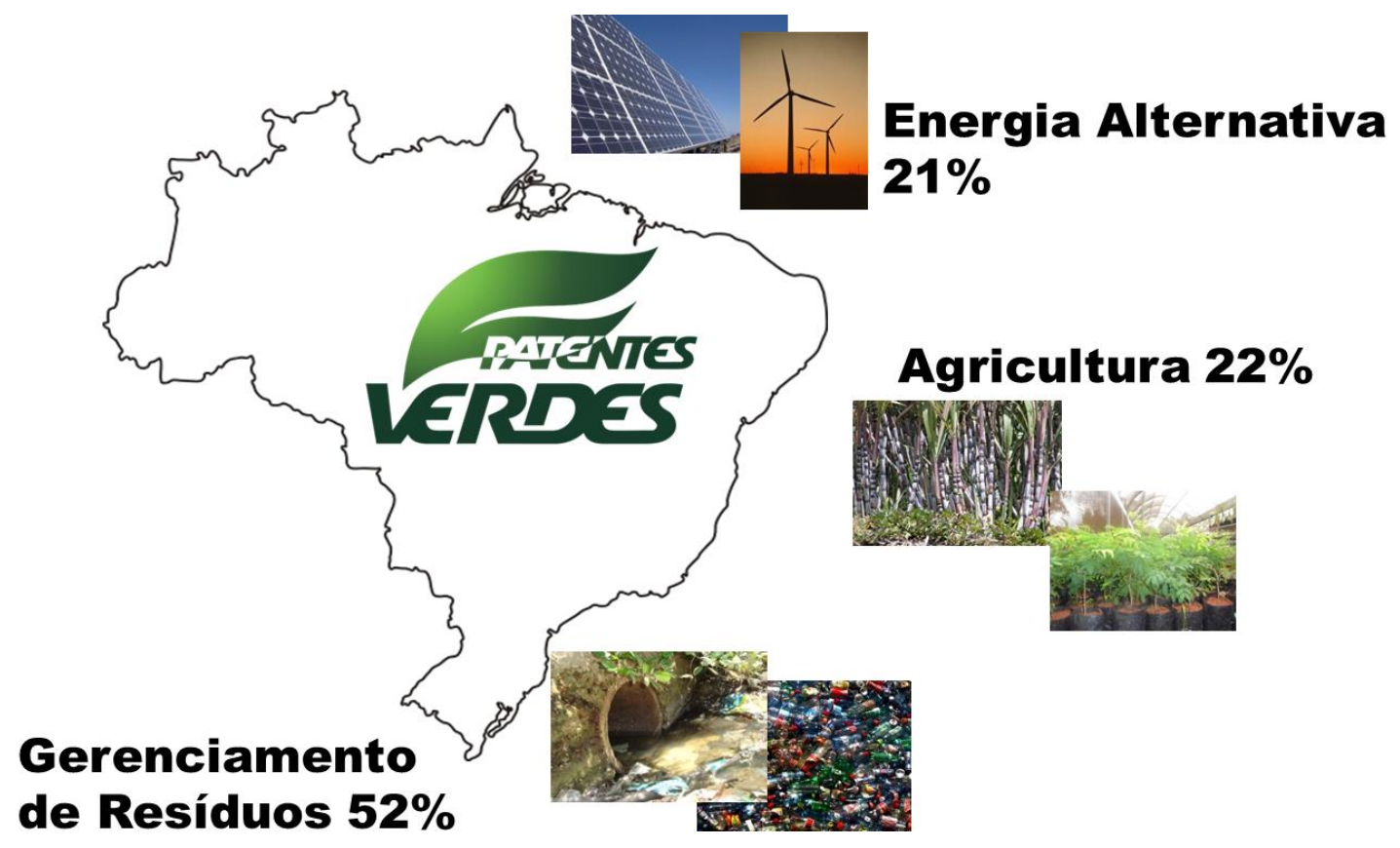

Figura 1 - Distribuição percentual das principais áreas de tecnologia. 


\section{9 a 22 de outubro de 2014 \\ Florianópolis/SC}

\section{CONSIDERAÇÕES FINAIS}

Se a concessão rápida de patentes é fundamental em qualquer área do conhecimento, para as tecnologias do setor energético é ainda mais importante. A concessão da patente, além de proteger e incentivar a criação, também permite ao inventor ter uma garantia adicional para demonstrar a viabilidade de retornos em pedidos de investimento para implantação da criação.

O cenário das Patentes Verdes é uma sinalização de importante avanço para a sociedade brasileira, privilegiando, simultaneamente, o incentivo à inovação e o desenvolvimento tecnológico de soluções sustentáveis. Ao fim, se aposta na proteção das patentes e na capacidade que esse valioso instrumento jurídico possa trazer para haver catalisação de investimentos para o setor.

Com relação ao tempo para uma patente ser concedida no INPI nota-se que o pedido PI1104733-0 foi concedido em cerca de 4 meses após a solicitação de entrada no PV; o pedido BR102012022280-9 foi concedido em cerca de 16 meses após a solicitação de entrada no PV; e, o pedido PI1101711-2 foi concedido em cerca de 21 meses após a solicitação de entrada no PV. Isto é, todos foram concedidos em menos de 2 anos tempo muito inferior ao tempo que levaria se estes pedidos não utilizassem a via "fast-track", tempo este que atualmente chega a ser superior a 10 anos.

Caso tais tecnologias fossem divulgadas em periódicos científicos $\mathrm{A} 1$, por exemplo na área Engenharia II, estes levariam mais de 2 anos para ser publicado, ou seja, mais tempo do que leva uma patente verde para ser concedida e sem garantia da proteção de mercado que a patente confere.

\section{REFERÊNCIAS}

CERVINO, A. C.; SÁNCHEZ, A. C. 2010. La innovación patentada en España en el sector de las tecnologías mitigadoras del cambio climático (1979-2008). Madrid: OEPM y Fundación EOI, 2010. $106 \mathrm{p}$.

DURÁN, R. F. Mudança climática: quem vai para o banco dos réus? Amai-vos, 20 nov. 2010. Disponível em: <http://amaivos.uol.com.br/amaivos09/noticia/print.asp? cod_noticia=16>. Acesso em: 20 maio 2011.

IDSO, Craig; SINGER, S. Fred. Climate Change Reconsidered: 2009 Report of the Nongovernmental Panel on Climate Change (NIPCC), Chicago, IL: The Heartland Institute, 2009. ISBN-13 - 978-1934791-28-8

INSTITUTO NACIONAL DA PROPRIEDADE INDUSTRIAL (INPI). Disponível em: <https://www.inpi.gov.br/menu-esquerdo/patente/pasta_oquee/ index_html>. Acesso em: 20 abr. 2014.

UNITED NATIONS FRAMEWORK CONVENTION ON CLIMATE CHANGE (UNFCCC).

Disponível em: <http://unfccc.int>. Acesso em: 19 abril 2014. 